\title{
예산지원(Budget Support)의 최신 동향과 과제
}

목차

I. 서론

II. 예산지원(Budget Support, BS)의 정의 및 지원 현황

1. 예산지원의 정의

2. 국제사회의 예산지원사업 현황

III . 예산지원사업의 효과성 평가

1. 예산지원사업 효과성 평가의 한계

2. 예산지원사업 효과성 평가 틀

3. 예산지원사업의 효과성

IV. 결론 및 시사점

참고 문헌 


\section{요 약}

새천년개발목표(Millenium Development Goals, MDGs)가 제시된 이후 국제사회는 원조의 효과성을 높이기 위해 다양한 정책적 노력을 진행해 왔다. 그리고 2000년대부터는 그 가운데 더 나은 원조일치와 원조조화, 낮은 거래비용, 높은 예측 가능성, 공공지출의 효율적 배분, 수원국의 효율적 공공재정 관리, 높은 책무성 및 주인 의식 등의 결과를 기대할 수 있는 예산지원이라는 사업 유형이 원조기관들로부터 많은 관심을 받기 시작 했다. 특히, 파리선언의 5대 원칙인 원조일치와 원조조화 개선에 도움이 되는 프로그램 기반 접근법(Programme-Based Approach, $\mathrm{PBA}$ )을 적용하는 데 가장 용이한 사업 유형으로 여겨져 많은 원조기관이 도입을 시도했다.

그러나 10 여 년이 지난 현재 많은 양자 공여국이 예산지원사업을 축소하고 있으며, 다자 공여기관들 정도만 기존 지원액을 유지하고 있다. 이는 여러 예산지원사업의 긍정 적인 평가에도 불구하고 해당 사업 유형에 대한 회의적인 시각과 여러 건의 수원국 정부 부패스캔들에 기인한다. 이는 예산지원사업과 수원국의 빈곤 감소 및 지속 가능하고 포용적인 경제성장의 직접적인 인과관계에 대한 근거를 찾을 수 없다는 평가 때문이기도 하다. 이로 인해 공여국의 예산지원사업이 보류 및 중단되어 지금까지 달성되었던 개발 결과의 효과를 예측하기 어렵게 되었다.

앞서 증명된 예산지원의 여러 긍정적인 효과가 지속적으로 유지되지 위해서는 예산지원 사업을 재정비해 다시 활성화할 필요가 있다. 예산지원사업이 모두 예측한 만병통치약이 아님을 인정하고, 이를 통해 얻을 수 있을 것으로 기대했던 많은 효과를 현실적인 수준으로 정리하는 일부터 시작해야 한다. 또한 단기적으로는 분야예산지원을 중심으로 재편하고, 부정적인 효과들을 상쇄할 수 있는 예산지원사업의 형성 및 이행 메커니즘을 찾아야 할 것이다. 그리고 예산지원과 빈곤 감소 사이의 직접적인 인과관계를 파악하는 것이 어렵다고는 하나, 교육과 보건 같은 사회 서비스에 대한 수혜자들의 접근이 개선된 것을 감안했을 때 장기적으로 비소득 빈곤의 감소는 기대해 볼 수 있을 것이다. 따라서 빈곤 감소라는 궁극적이며 장기적인 목표 달성을 확인할 수 있는 논리적인 평가 틀이 마련되어야 할 것으로 보인다. 


\section{I . 서론}

새천년개발목표(Millenium Development Goals, MDGs)가 제시된 이후 국제사회는 원조의

효과성을 높이기 위해 다양한 정책적 노력을 진행해 왔다. 그리고 2000년대부터는 그 가운데

수원국의 주인 의식 제고 및 책무성 강화에 기여하고, 국제사회가 지향하는 비구속성 원조로 구분될 수 있는 예산지원이라는 사업 유형이 원조기관들로부터 많은 관심을 받기 시작했다.

특히, 파리선언의 5대 원칙인 원조일치와 원조조화의 개선에 도움이 되는 프로그램 기반 접근법 (Programme-Based Approach, PBA)을 적용하는 데 가장 용이한 사업 유형(type of aid)으로 여겨져 많은 원조기관이 도입을 시도했다. 예산지원사업의 본격적인 도입과 함께 국제사회는 더 나은 원조일치와 원조조화, 낮은 거래비용, 높은 예측 가능성, 공공지출의 효율적 배분, 수원국의 효율적 공공재정 관리, 높은 책무성 및 주인 의식 등을 기대했다.

이에 본 연구는 예산지원사업이 활성화된 이후 10 여 년이 지난 지금 국제사회가 기대했던 개발 효과가 나타났는지, 현재는 예산지원사업이 어떤 양상을 띠고 있는지에 관해 최신 동향과 함께 앞으로의 과제에 대해 살펴보고자 한다. 


\section{II. 예산지원(Budget Support, BS)의 정의 및 지원 현황}

\section{1. 예산지원의 정의}

경제협력개발기구(Organization for Economic Cooperation and Development, 이하 $\mathrm{OECD})$ 는 예산지원과 관련해 공여국의 재원이 수원국의 국고로 편입되어 수원국의 예산을 지원하는 원조 양식이라고 정의하고 있다. 예산지원은 일반예산지원(General Budget Support, GBS)과 분야예산지원(Sector Budget Support, SBS)으로 구분되는데, 일반예산지원은 사용처를 지정하지 않고(non-earmarked) 지원하는 것이고, 분야예산지원은 특정 분야에 사용하도록 지정한 예산지원을 의미한다. 예산지원은 단독으로 지원되기보다는 일반적으로 다른 비재정지원과 같이 제공되는데, 주로 정책대화(policy dialogue), 지출조건(disbursement conditions), 기술 지원(technical assistance), 역량개발(capacity development) 등이 여기에 포함된다. 예산 지원이 다른 비재정지원과 같이 제공되는 이유는 이러한 지원들과 같이 제공되었을 때 사업의 효과성을 좀 더 많이 기대할 수 있기 때문이다. 비재정지원은 예산 수립, 책정, 집행 등의 일련의 과정에서 발생할 수 있는 애로 사항들을 처리하고 수원국의 시스템을 개선하는 데 기여한다고 평가되고 있다.1)

〈표 1〉 예산지원의 종류

\begin{tabular}{|c|c|c|}
\hline $\begin{array}{l}\text { 유형/하위 } \\
\text { 유형 } \\
\text { (Type/ } \\
\text { Sub-type) }\end{array}$ & $\begin{array}{c}\text { 제목 } \\
\text { (Description) }\end{array}$ & $\begin{array}{c}\text { 설명 } \\
\text { (Clarification) }\end{array}$ \\
\hline A & $\begin{array}{c}\text { 예산지원 } \\
\text { (Budget Support) }\end{array}$ & $\begin{array}{l}\text { 본 범주에 속하는 자금 지원의 경우, 공여국은 수원국과 책임을 분담해 } \\
\text { 해당 기금의 배타적 운영권을 포기한다. } \\
\text { (For contributions under this category, the donor relinquishes } \\
\text { the exclusive control of its funds by sharing the responsibility } \\
\text { with the recipient.) }\end{array}$ \\
\hline $\mathrm{A} 01$ & $\begin{array}{l}\text { 일반예산지원 } \\
\text { (General Budget } \\
\text { Support) }\end{array}$ & $\begin{array}{l}\text { 거시경제 개혁을 지원하기 위한 자금지원 등 정부 예산에 제공하는 } \\
\text { 비지정 기여다.(예: 구조조정 프로그램, 빈곤감소 전략) } \\
\text { (Unearmarked contributions to the government budget including } \\
\text { funding to support the implementation of macroeconomic reforms } \\
\text { (structural adjustment programmes, poverty reduction strategies).) }\end{array}$ \\
\hline
\end{tabular}

1) 그러나 독일개발평가연구소(German Institute for Development Evaluation, DEval)에 따르면, 이런 비재정지원 각각의 개별적인 효과에 대한 정보는 예산지원 평가 보고서들에서 거의 찾아볼 수 없다고 애기하고 있다(Magdalena, Schmitt, Krisch, and Oltsch, 2017). 


\begin{tabular}{|c|c|c|}
\hline $\begin{array}{c}\text { 유형/하위 } \\
\text { 유형 } \\
\text { (Type/ } \\
\text { Sub-type) }\end{array}$ & $\begin{array}{c}\text { 제목 } \\
\text { (Description) }\end{array}$ & $\begin{array}{c}\text { 설명 } \\
\text { (Clarification) }\end{array}$ \\
\hline & & $\begin{array}{l}\text { 예산지원이란 외부 지원기관으로부터 수원국의 국고로 재원을 이전해 } \\
\text { 수원국 예산을 지원히는 방식이다. 이전된 기금은 수원국의 예산 절차에 따라 } \\
\text { 관리한다. 자금지원 프로그램 또는 프로젝트를 위해 국고로 이전된 } \\
\text { 기금은 수원국마다 상이한 예산 절차에 따라 관리한다. 따라서 자금의 } \\
\text { 용처를 특정한 목적으로 지정한 경우는 예산지원에 해당하지 않는다. } \\
\text { (Budget suppport is a method of financing a recipient country' } \mathrm{s} \\
\text { budget through a transfer of resources from an external } \\
\text { financing agency to the recipient government' } \mathrm{s} \text { national } \\
\text { treasury. The funds thus transferred are managed in accordance } \\
\text { with the recipient' s budgetary procedures. Funds transferred } \\
\text { to the national treasury for financing programmes or projects } \\
\text { managed according to different budgetary procedures from } \\
\text { those of the recipient country, with the intention of earmarking } \\
\text { the resources for specific uses, are therefore excluded.) }\end{array}$ \\
\hline A02 & $\begin{array}{l}\text { 분야예산지원 } \\
\text { (Sector Budget } \\
\text { Support) }\end{array}$ & $\begin{array}{l}\text { 분야예산지원은 일반예산지원과 마찬가지로 수원국 예산에 제공하는 } \\
\text { 지원이다. 단, 분야예산지원의 경우, 공여국과 파트너 정부 간의 정책 } \\
\text { 논의는 전반적인 정책 및 예산 우선순위가 아닌 특정한 분야에 집중한다. } \\
\text { (Sector budget support, like general budget support, is a } \\
\text { financial contribution to a recipient government' } \mathrm{s} \text { budget. } \\
\text { However, in sector budget support, the dialogue between } \\
\text { donors and partner governments focuses on sector-specific } \\
\text { concerns, rather than on overall policy and budget priorities.) }\end{array}$ \\
\hline
\end{tabular}

출처: OECD (2018), 한국국제협력단 (2016)을 참고해 저자가 재구성

\section{2. 국제사회의 예산지원사업 현황}

개발원조위원회(Development Assistance Committee, 이하 DAC) 통계를 살펴보면, 일반 예산지원이 2002년부터 시작된 것을 확인할 수 있는데, 이는 DAC 통계 지침의 공여국 보고 체계(Creditor Reporting System, 이하 CRS) 목적코드 중 일반예산지원을 구분하는 목적코드 51010 로 데이터가 구분되었기 때문이다. 당시 통계 지침은 일반예산지원을 사업 유형이 아닌 $\mathrm{CRS}$ 목적코드로 구분하고 있었으며, 분야예산지원을 구분하는 $\mathrm{CRS}$ 코드는 아예 존재하지 않았다. 그러나 2010년 통계 지침이 개정되어 사업 유형에 예산지원이라는 상위 카테고리가 만들어졌고, 그 하위에 A01로 구분하는 일반예산지원과 A02로 구분하는 분야예산지원이 새롭게 도입되면서 이들 데이터가 수집되었다.2) 따라서 기존 CRS 목적코드 51010으로 구분되는 일반

2) $\mathrm{ODA}$ 통계를 검색하게 되면, 일반예산지원은 2002년부터 데이터를 확인할 수 있고, 예산지원과 분야예산지원은 2010년 부터 데이터를 확인할 수 있다. 
예산지원과 새롭게 도입된 사업 유형의 $\mathrm{A} 01$ 로 구분되는 일반예산지원의 차이는 거의 없다고 보는 것이 무방하다.

〈표 2〉DAC 공여국 전체 예산지원 지원액

\begin{tabular}{|c|c|c|c|c|c|c|c|c|}
\hline & 2002 & 2003 & 2004 & 2005 & 2006 & 2007 & 2008 & 2009 \\
\hline ODA & 65,943 & 80,331 & 92,929 & 119,073 & 118,317 & 117,929 & 137,296 & 132,464 \\
\hline 예산지원(BS) & 0 & 0 & 0 & 0 & 0 & 0 & 0 & 0 \\
\hline 일반예산지원(GBS) & 1,414 & 2,351 & 1,359 & 1,826 & 2,232 & 2,687 & 3,263 & 3,176 \\
\hline 분야예산지원(SBS) & 0 & 0 & 0 & 0 & 0 & 0 & 0 & 0 \\
\hline 예산지원 비중(\%) & 0 & 0 & 0 & 0 & 0 & 0 & 0 & 0 \\
\hline 일반예산지원 비중(\%) & $2.1 \%$ & $2.9 \%$ & $1.5 \%$ & $1.5 \%$ & $1.9 \%$ & $2.3 \%$ & $2.4 \%$ & $2.4 \%$ \\
\hline 분야예산지원 비중(\%) & 0 & 0 & 0 & 0 & 0 & 0 & 0 & 0 \\
\hline & 2010 & 2011 & 2012 & 2013 & 2014 & 2015 & 2016 & \\
\hline ODA & 141,334 & 150,194 & 140,247 & 151,785 & 151,142 & 143,132 & 157,574 & \\
\hline 예산지원(BS) & 4,461 & 4,050 & 2,752 & 5,851 & 3,038 & 2,946 & 2,541 & \\
\hline 일반예산지원(GBS) & 2,451 & 2,036 & 1,647 & 4,042 & 1,120 & 1,031 & 1,090 & \\
\hline 분야예산지원(SBS) & 2,011 & 2,015 & 1,105 & 1,810 & 1,918 & 1,915 & 1,450 & \\
\hline 예산지원 비중(\%) & $3.2 \%$ & $2.7 \%$ & $2.0 \%$ & $3.9 \%$ & $2.0 \%$ & $2.1 \%$ & $1.6 \%$ & \\
\hline 일반예산지원 비중(\%) & $1.7 \%$ & $1.4 \%$ & $1.2 \%$ & $2.7 \%$ & $0.7 \%$ & $0.7 \%$ & $0.7 \%$ & \\
\hline 분야예산지원 비중(\%) & $1.4 \%$ & $1.3 \%$ & $0.8 \%$ & $1.2 \%$ & $1.3 \%$ & $1.3 \%$ & $0.9 \%$ & \\
\hline
\end{tabular}

출처: OECD 통계(http://stats.oecd.org)를 참고해 저자가 재구성 (단위: 백만 달러, 총지출 기준)

<표 2>를 보면, 2002년부터 2009년까지 DAC 공여국 전체 공적개발원조(Official Development Assistance, 이하 ODA) 중 약 $2 \%$ 정도를 일반예산지원에 투입했다는 것을 알 수 있다. 그러나 2010년 이후 이 수치가 $1 \%$ 대를 기록하며 일반예산지원이 점점 줄어들고 있는 상황이다. 반면, 2010년부터 실적을 확인할 수 있는 분야예산지원은 2014년에 처음으로 일반예산지원보다 금액이 많아졌으며, 전체 ODA 중 분야예산지원이 차지하는 비중도 기존과 비슷하게 유지되고 있다. 


\section{〈그림 1〉 DAC 공여국의 일반예산지원 및 분야예산지원 지원액}

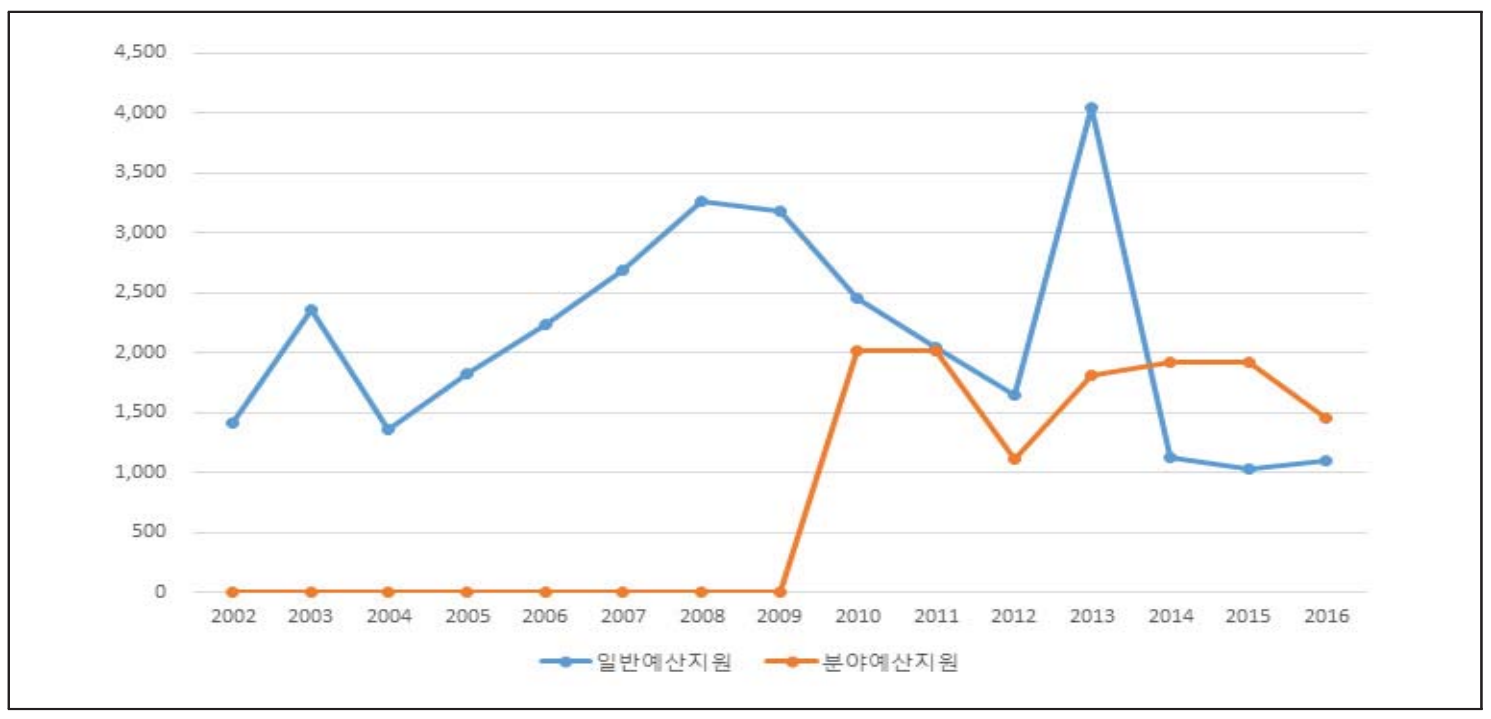

출처: OECD 통계(http://stats.oecd.org)를 참고해 저자가 재구성

(단위: 백만 달러, 총지출 기준)

한편, <표 3>에서 보는 바와 같이 DAC 공여국 중 일반예산지원사업을 많이 하고 있는 국가는 프랑스, 독일, 일본, 영국, 미국으로 이들 국가의 일반예산지원사업은 DAC 공여국 전체 일반예산지원사업의 66 93\%를 차지하고 있다. 결국, 수원국에 지원되는 예산지원의 대부분이 이들 5 개 국가의 지원으로 이루어져 있다는 것을 알 수 있다. 특히, 2013년의 경우에는 일본이 이례적으로 일반예산지원사업을 늘려 2009년 이후 축소되는 경향을 보이던 일반예산지원이 잠시 증가하는 모습을 보였다. 그러나 전체적으로 보았을 때 앞서 언급했던 것처럼 일반예산 지원은 줄어들고 있는 양상을 보인다.

\section{〈표 3〉DAC 5대 공여국 일반예산지원 지원액}

\begin{tabular}{|c|c|c|c|c|c|c|c|c|}
\hline & 2002 & 2003 & 2004 & 2005 & 2006 & 2007 & 2008 & 2009 \\
\hline $\mathrm{DAC}$ 공여국 전체 ODA & 65,943 & 80,331 & 92,929 & 119,073 & 118,317 & 117,929 & 137,296 & 132,464 \\
\hline $\mathrm{DAC}$ 공여국 전체 GBS & 1,414 & 2,351 & 1,359 & 1,826 & 2,232 & 2,687 & 3,263 & 3,176 \\
\hline $\begin{array}{l}\text { DAC 전체 ODA 대비 GBS } \\
\text { 비중(\%) }\end{array}$ & $2.1 \%$ & $2.9 \%$ & $1.5 \%$ & $1.5 \%$ & $1.9 \%$ & $2.3 \%$ & $2.4 \%$ & $2.4 \%$ \\
\hline 프랑스 GBS & 227 & 54 & 55 & 59 & 272 & 300 & 702 & 260 \\
\hline 독일 GBS & 4 & 0 & 55 & 56 & 88 & 73 & 58 & 136 \\
\hline 일본 GBS & 247 & 264 & 157 & 191 & 122 & 443 & 255 & 950 \\
\hline 영국 GBS & 341 & 520 & 606 & 531 & 691 & 690 & 746 & 541 \\
\hline 미국 GBS & 360 & 1131 & 12 & 455 & 377 & 275 & 506 & 428 \\
\hline $\begin{array}{l}\text { DAC 전체 GBS 대비 5개국 } \\
\text { GBS 비중(\%) }\end{array}$ & $83.3 \%$ & $83.7 \%$ & $65.1 \%$ & $70.7 \%$ & $69.4 \%$ & $66.3 \%$ & $69.5 \%$ & $72.9 \%$ \\
\hline
\end{tabular}




\begin{tabular}{l|r|r|r|r|r|r|r}
\hline & \multicolumn{1}{|c|}{2010} & \multicolumn{1}{|c|}{2011} & \multicolumn{1}{|c}{2012} & \multicolumn{1}{|c}{2013} & 2014 & 2015 & 2016 \\
\hline DAC 공여국 전체 ODA & 141,334 & 150,194 & 140,247 & 151,785 & 151,142 & 143,132 & 157,574 \\
\hline DAC 공여국 전체 GBS & 2,451 & 2,036 & 1,647 & 4,042 & 1,120 & 1,031 & 1,090 \\
\hline $\begin{array}{l}\text { DAC 전체 ODA 대비 GBS } \\
\text { 비중(\%) }\end{array}$ & $1.7 \%$ & $1.4 \%$ & $1.2 \%$ & $2.7 \%$ & $0.7 \%$ & $0.7 \%$ & $0.7 \%$ \\
\hline 프랑스 GBS & 259 & 563 & 261 & 251 & 217 & 231 & 174 \\
\hline 독일 GBS & 97 & 151 & 58 & 37 & 39 & 12 & 3 \\
\hline 일본 GBS & 665 & 67 & 165 & 2569 & 368 & 198 & 753 \\
\hline 영국 GBS & 163 & 215 & 349 & 211 & 87 & 76 & 81 \\
\hline 미국 GBS & $66.7 \%$ & $70.9 \%$ & $73.5 \%$ & $90.3 \%$ & $79.2 \%$ & $78.1 \%$ & $93.4 \%$ \\
\hline $\begin{array}{l}\text { DAC 전체 GBS 대비 5개국 } \\
\text { GBS 비중(\%) }\end{array}$ & & & & & 177 & 288 & 7 \\
\hline
\end{tabular}

출처: OECD 통계(http://stats.oecd.org)를 참고해 저자가 재구성

(단위:백만 달러, 총지출 기준)

$\mathrm{DAC}$ 통계를 찾아보면 예산지원사업을 가장 활발하게 추진하고 있는 공여국은 양자가 아닌 다자 유럽연합(European Union, 이하 EU)인 것으로 확인된다. 아래 <표 4>에서 보는 것처럼 $\mathrm{EU}$ 는 2002년부터 일반예산지원을 시작해 그 비중이 $\mathrm{EU}$ 전체 $\mathrm{ODA}$ 중 약 7 9\%를 차지했고, 2010년에는 처음으로 10\%대를 넘어 12.1\%를 기록하고 또 2011년부터 5\%대로 축소되기 시작 했다. 그리고 2016 년에는 3.5\%로 떨어져 일반예산지원을 점점 축소하고 있는 것으로 나타났다. 반면, 분야예산지원은 2010년에서 2012년 사이 줄어들다가 그 이후 다시 늘어나는 경향을 보이고 있다.

〈표 4〉 EU 예산지원 지원액

\begin{tabular}{l|r|r|r|r|r|r|r|r}
\hline & 2002 & 2003 & 2004 & 2005 & 2006 & 2007 & 2008 & 2009 \\
\hline ODA & 5792 & 7393 & 8971 & 9726 & 10678 & 11743 & 13197 & 13583 \\
\hline 예산지원(BS) & 0 & 0 & 0 & 0 & 0 & 0 & 0 & 0 \\
\hline 일반예산지원(GBS) & 440 & 490 & 650 & 948 & 843 & 833 & 798 & 1184 \\
\hline 분야예산지원(SBS) & 0 & 0 & 0 & 0 & 0 & 0 & 0 & 0 \\
\hline 예산지원 비중(\%) & 0 & 0 & 0 & 0 & 0 & 0 & 0 & 0 \\
\hline 일반예산지원 비중(\%) & $7.6 \%$ & $6.6 \%$ & $7.2 \%$ & $9.7 \%$ & $7.9 \%$ & $7.1 \%$ & $6.0 \%$ & $8.7 \%$ \\
\hline 분야예산지원 비중(\%) & 0 & 0 & 0 & 0 & 0 & 0 & 0 & 0 \\
\hline & 2010 & 2011 & 2012 & 2013 & 2014 & 2015 & 2016 \\
\hline & 12889 & 18292 & 18388 & 17401 & 18516 & 15679 & 18902 \\
\hline ODA & 2805 & 2306 & 2253 & 2285 & 2221 & 1852 & 2067 \\
\hline 예산지원(BS) & 1563 & 1031 & 1039 & 931 & 1213 & 816 & 657 & \\
\hline 일반예산지원(GBS) & 1242 & 1275 & 1214 & 1354 & 1008 & 1036 & 1410 \\
\hline 분야예산지원(SBS) & $21.8 \%$ & $12.6 \%$ & $12.3 \%$ & $13.1 \%$ & $12.0 \%$ & $11.8 \%$ & $10.9 \%$ \\
\hline 예산지원 비중(\%) & $12.1 \%$ & $5.6 \%$ & $5.6 \%$ & $5.4 \%$ & $6.5 \%$ & $5.2 \%$ & $3.5 \%$ \\
\hline 일반예산지원 비중(\%) & $12.6 \%$ & \\
\hline 분야예산지원 비중(\%) & $9.6 \%$ & $7.0 \%$ & $6.6 \%$ & $7.8 \%$ & $5.4 \%$ & $6.6 \%$ & $7.5 \%$ \\
\hline
\end{tabular}

출처: OECD 통계(http://stats.oecd.org)를 참고해 저자가 재구성

(단위: 백만 달러, 총지출 기준) 
<그림 2>는 일반예산지원사업을 하는 상위 5 대 국가와 $\mathrm{EU}$ 의 지원액을 비교한 그래프다. 그래프에서 보는 바와 같이, 2013년을 제외하면 2009년 이후로 양자 공여국가들이 다자 공여 기관인 EU에 비해 일반예산지원을 줄이고 있는 속도가 빠르며 또 영국, 미국, 독일의 경우에는 2016년 지원액이 아주 미미한 수준이다.

\section{〈그림 2〉 상위 5대 DAC 공여국 및 EU의 일반예산지원 지원액}

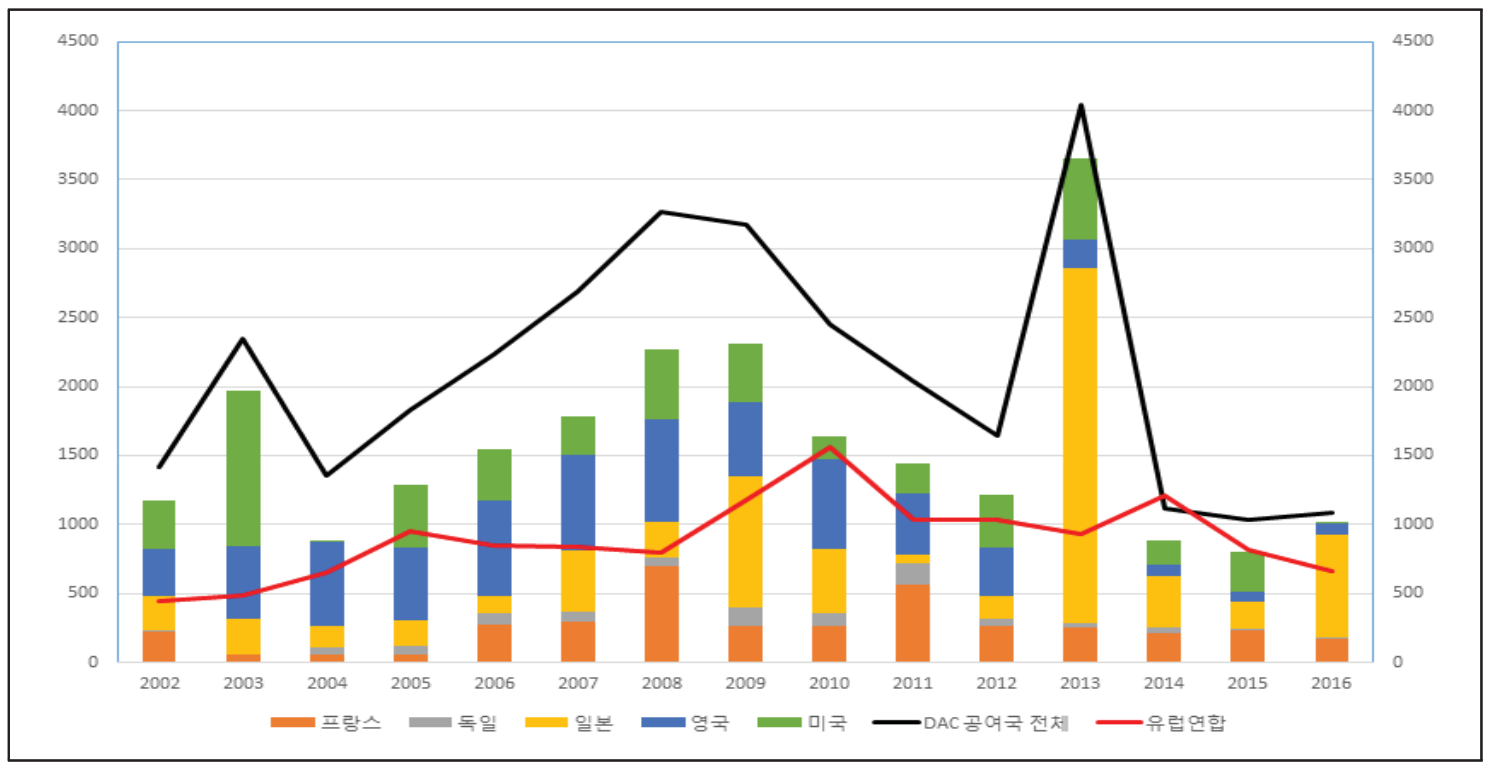

출처: OECD 통계(http://stats.oecd.org)를 참고해 저자가 재구성

(단위: 백만 달러, 총지출 기준)

결국, $\mathrm{DAC}$ 공여국과 $\mathrm{EU}$ 모두 기존에 주를 이루던 일반예산지원이 줄어들고, 이를 대체하기 위해 분야예산지원이 늘어나고 있는 것이다. 독일개발평가연구소(German Institute for Development Evaluation, 이하 DEva)는 양자 원조 포트폴리오를 보면 개발원조의 방향이 분야예산지원 쪽으로 많이 기울어져 있는 것을 확인할 수 있다고 지적한다. 그리고 중소득국의 수원국 또한 분야예산지원과 함께 특정 분야의 기술 지원 및 역량 개발을 적극 요구하고 있다고 주장한다(Krisch and Schmitt, 2015). 3장 예산지원사업의 효과성 평가에서 언급하겠지만, 예산지원사업이 교육과 보건 분야의 공공지출을 증대시켰고, 해당 서비스에 대한 수혜자들의 접근성이 개선되는 긍정적인 효과가 있다는 평가를 받고 있다. 이러한 평가 결과로 짐작해 보면, 일반예산지원사업의 효과성에 대한 회의적인 시각이 사업의 효과성을 확인할 수 있는 분야예산지원사업의 지원액 증가로 나타나고 있는 것으로 분석해 볼 수 있다. 다시 말해, 전체 $\mathrm{ODA}$ 에서 예산지원이 차지하는 비중은 점점 줄어들고 있으며, 그 안에서 일반예산지원은 축소 되고 분야예산지원만 현재의 지원 규모를 유지하고 있는 것이다. DEval의 보고서에 따르면, 실제로도 많은 공여국이 예산지원사업을 줄이고 있다고 언급하고 있다. 또한 공여국들이 예산지원 
사업을 줄이거나 보류하게 된 이유가 수원국의 부패와 사업 유형 자체에 대한 회의론이 늘어나고 있기 때문이라고 분석하고 있다(Orth and Schmitt, 2018a). 실제로, 독일을 비롯한 여러 양자 공여국이 2012 2013년 이후로 일반예산지원을 거의 하지 않고 있으며, 다자공여기관들만 해당 사업 유형을 유지하고 있다고 지적하고 있다. 말리·우간다·잠비아는 정부의 부패 스캔들로, 르완다는 콩고민주공화국 내 투치 반군을 지원하고 있다는 게 밝혀져 2012년부터 2014년까지 예산지원사업이 중단되었다(Orth, Birsan, and Gotz, 2018b). 


\section{III. 예산지원사업의 효과성 평가}

\section{1. 예산지원사업 효과성 평가의 한계}

그렇다면 예산지원사업의 효과성이 실제로 좋지 않게 평가되고 있는지 살펴보도록 하자. 사실, 예산지원사업의 효과성을 평가하는 것은 쉬운 일이 아니다. 이러한 평가를 진행하는 데는 네 가지의 어려움이 존재한다(Dijkstra and de Kemp, 2015). 첫째, 예산 지원의 영향력을 평가하기 위해 사후가정(counterfactual) 방법을 엄밀하게 적용할 수 없다는 것이다. 즉, 예산 지원은 국가 차원의 목표를 달성하기 위해 정부에 지원되기 때문에 효과성을 보기 위한 무작위 대조군 연구(randomized controlled trial, RCT)를 수행할 수 없다는 문제가 있다. 둘째, 예산지원사업의 효과성이 모호하다는 것이다. 예산지원사업이 프로젝트형 사업보다 효과적인지, 아니면 국제수지지원(balance of payment) 같은 기존의 프로그램형 원조보다 효과적인지에 대한 명확한 구분·비교가 없는 상황이다. 셋째, 예산지원사업이 상반되는 두 가지의 목표를 추구한다는 것이다. 예산지원은 수원국의 주인 의식을 제고하고, 이를 통해 빈곤 감소와 예산 지원을 더욱 효과적으로 추진하고 또 이와 함께 제공되는 비재정지원을 통한 수원국의 거버넌스와 정책 개선을 목표로 한다. 그러나 후자는 전자를 훼손시킬 수 있는 성질을 가지고 있다. 넷째, 예산지원은 기본적으로 여러 공여국이 공동으로 지원하는 경우가 많다. 따라서 이들 국가들이 우선 고려 사항, 선호도, 지출 절차 등을 합의하는 과정에서 나타나는 조화와 대립이 예산지원의 효과를 강화시킬 수도 훼손시킬 수도 있다는 것이다.

\section{2. 예산지원사업 효과성 평가 틀}

이러한 한계점을 인식해서인지 대부분의 예산지원사업의 평가는 기존 사업 유형과의 효과성을 비교하는 구조가 아닌 변화이론에 맞춰 예산지원사업이 기대했던 변화를 가져왔는지, 그 변화가 예산지원사업에 기인한 것인지 아니면 해당 변화의 원인이 다른 요소에 있는 것인지를 평가하는 것으로 구성되어 있다. 즉, 예산지원사업이 수원국의 정책, 전략, 지출 활동을 어떤 상황에서 얼마나 강화시켰고 또 그로 인해 국가 전체 또는 특정 분야의 지속 가능한 개발성과 달성, 빈곤 감소에 긍정적인 영향, 지속 가능하며 포용적인 경제성장을 이루었는지에 평가의 초점을 두고 있다. 그러나 이러한 변화이론에 기반을 둔 평가조차도 예산지원사업과 빈곤 감소 및 지속 가능하고 포용적인 경제성장이라는 효과 사이의 탄탄한 인과관계를 증명해 내기 어렵다는 것을 인정하고 평가 틀을 수정했다. 대표적인 예로, OECD가 2006년에 제시한 5단계 평가 
〈그림 3〉 $\mathrm{OECD}$ 의 예산지원사업 5단계 평가 틀

\begin{tabular}{|c|}
\hline $\begin{array}{c}\text { 1단계 : 일반예산지원/분야예산지원 투입(GBS/SBS inputs) } \\
\text { (수원국 자체적인 여러 투입 및 다른 외부 지원 프로그램 투입도 포함) }\end{array}$ \\
$\downarrow$ \\
$\begin{array}{c}\text { 2단계 : 직접적인 산출(Direct Outputs) } \\
\text { 수원국 내 예산 및 정책 과정과 외부 지원 사이의 관계 개선 } \\
\text { (수원국 자체 투입 및 다른 외부 지원 프로그램 투입에 의한 결과도 포함) }\end{array}$ \\
$\downarrow$ \\
3단계 : 부가적인 산출(Induced Outputs) \\
공공정책, 공공부문제도, 공공지출, 공공서비스 전달의 개선 \\
$\quad \downarrow$ \\
4단계 : 결과(Outcomes) \\
정부의 정책 관리 및 서비스 전달에 대한 수혜자(서비스 사용자와 경제주체)의 긍정적 응답 \\
\hline \\
5단계 : 효과(Impact) \\
지속 가능하고 포용적인 성장 및 빈곤 감소 \\
\hline
\end{tabular}

출처: OECD (2012:9)를 참고해 저자가 재구성

$\mathrm{OECD}(2012)$ 는 예산지원사업의 효과성을 평가하는 데 있어서 3단계로 평가하는 틀(framework)을 제시하고 있다. 위<그림 3>에서 보는 바와 같이 기존에는 세계은행(World Bank)에서 제시한 것처럼 5단계 틀을 제안했으나, 예산지원사업과의 직접적인 인과관계 분석(causality analysis)이 가능한 1, 2단계와 3단계 일부를 묶어 Step1로, 나머지 3단계와 4, 5단계를 묶어 Step2로, 그리고 Step1과 Step2를 통합적으로 살피며 예산지원이 수원국의 정부 정책 및 전략의 성공 또는 실패에 기여했는지를 보는 Step3으로 수정·제시했다. 이는 3, 4, 5단계가 예산지원사업의 결과로만 얻어지는 것이 아닌 다른 여러 개발 주체(시민사회, 민간 부문 등)와 프로젝트 또는 외부 요소(세계시장의 자본재 가격, 외부 자본 유입, 정치적 안정)에 의해서도 영향을 받을 수 있기 때문이라는 분석에 기인한다(Koeberle, Stavreski, and Walliser, 2006). 또한 $\mathrm{OECD}(2012)$ 는 빈곤 감소 및 경제개발 부양을 위한 수원국의 공공지출 결과 및 효과가 국가 전략과 정책의 질, 추진하고자 하는 의지, 이를 위해 자원을 효과적·효율적으로 사용하고자 하는 정치적·행정적 역량에 의해 결정되기 때문이라고 지적하고 있다. 


\section{〈그림 4〉OECD의 예산지원사업 3단계 평가 틀}

Step1 : 예산지원의 투입, 직접적인 산출, 부가적인 산출(5단계 틀의 $1,2,3$ 단계)에 대한 평가 및 이들 간의 원인 및 결과 관계 분석(analysis of the causal links)

Step2 : 수원국 정부가 목표한 기대 결과 및 효과(expected outcomes and impact), 실제 결과 및 효과(actual outcomes and impact)에 대한 평가와 이들 결과 및 효과의 주요 결정 요소들 확인(5단계 틀의 4,5 단계)

출처: OECD (2012:14)를 참고해 저자가 재구성

이렇게 수정·변경한 3 단계 평가 틀에서도 한계는 존재한다. 예산지원이 정부 정책, 전략 및 지출에 어떤 기여를 했는지 분석한다는 Step3에서 우리는 정량적인 기여수치의 도출을 기대하지만, 이는 대부분 불가능하다. 그래서 기여도는 논리적 추론과 논리적 연결고리의 확인을 통한 질적 평가로 확인해야 한다(OECD, 2012).

\section{3. 예산지원사업의 효과성}

이러한 평가의 어려움에도 불구하고 예산지원의 효과성을 평가하는 많은 보고서는 예산지원이 효과적이라는 결론을 내리고 있다(Koeberle et al., 2006; Fiscus, 2014; Lawson 2015; ADE, 2013c; EU, 2017; Orth et al., 2018a). 해당 사업의 유형이 공공서비스 조달 개선, 빈곤 감소에 기여했으며 또 예산지원을 받은 수원국의 경제 거버넌스, 공공재정 관리, 예산의 투명성 등이 강화된 것으로 평가되었다. 이러한 긍정적인 변화는 부패 척결·개선으로도 나타나고 있다. 특히, 32 개 예산지원 평가보고서 및 42개 학술 발간물을 종합 평가한 DEval(2018a)은 아래<그림 $5>$ 와 같이 예산지원의 효과를 제시하며, 예산지원의 긍정적인 효과를 다음과 같이 정리하고 있다. 예산지원이 공공지출, 특히 교육과 보건사회 분야의 지출을 확대하는 데 기여했으며, 수원국 공공재정 관리의 품질(특히 예산 계획 및 준비, 예산 투명성)에 긍정적인 효과를 가져왔다. 또한 수원국의 국내 책무성의 공급 측면(재정부와 통계청 같은 기관의 효율성, 최상위 감사기관의 역할 및 효율성)을 강화시켰고, 공공서비스(특히 교육과 보건)에 대한 접근을 개선했으며, 수원국의 거시경제 안정성의 증진 및 국내 부채 상환에 기여했다. 


\section{〈그림 5〉예산지원의 효과}

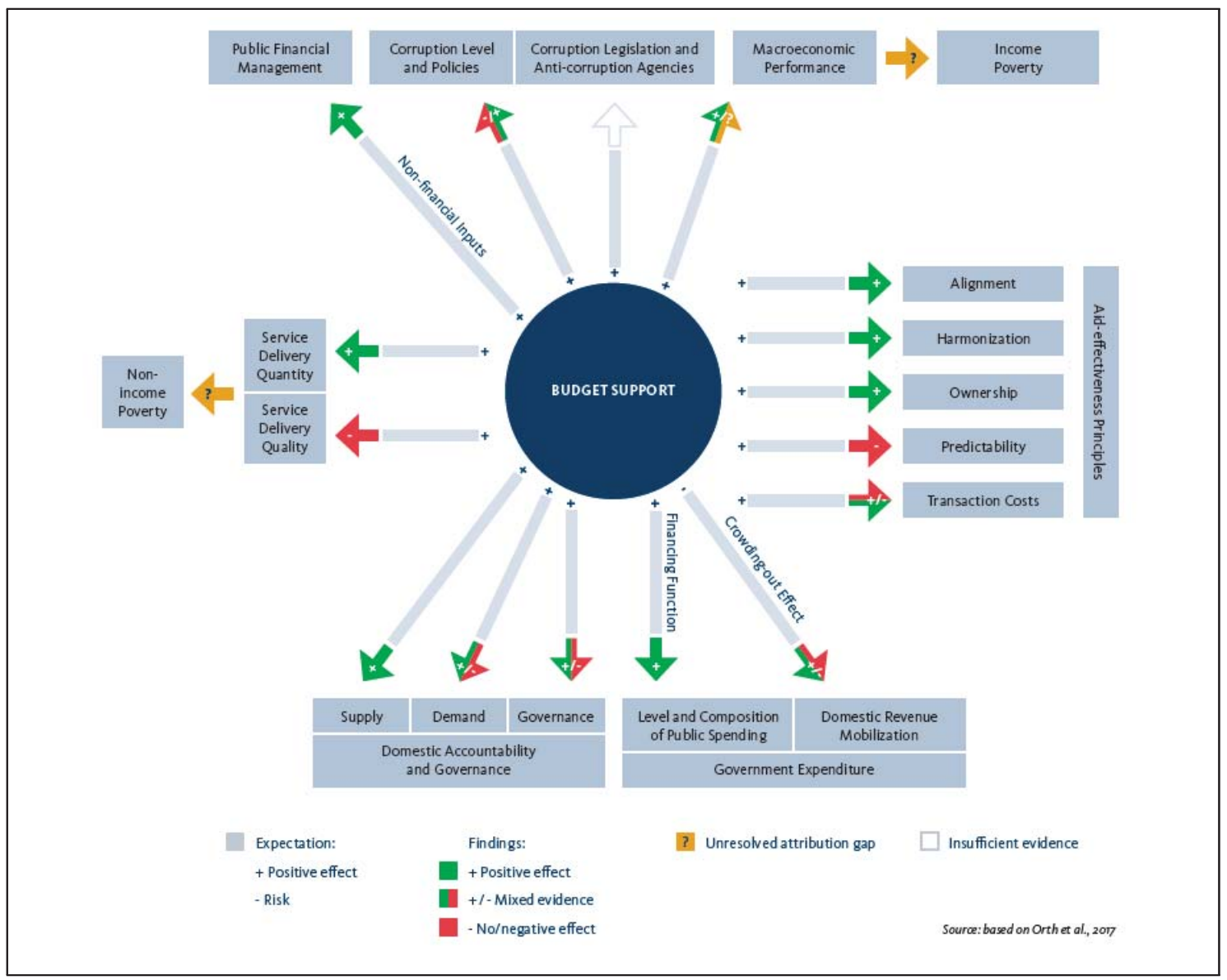

출처: Orth et al. (2018a)

한편, 보고서는 예산지원사업이 수원국의 부패를 척결하는 데 기여한 것과 관련해 조금 다른 입장을 나타내며, 대부분의 평가 보고서들이 예산지원과 관련해 부패의 위험성이 있다는 것을 거의 언급하지 않고 있음을 강조하고 있다. 그리고 예산지원이 부패 위험을 감소시킨다는 근거가 없을 뿐만 아니라 유효한 근거조차도 예산지원이 실제로 부패 위험을 줄일 수 있는지 입증하지 못하고 있음을 지적하고 있다. 또한 국내 책무성의 수요 측면(국회, 시민사회, 언론 등)에 대한 예산지원의 장기적 효과도 확인되지 않았다고 언급하고 있다. 뿐만 아니라 공공서비스의 품질 개선에 영향을 주었는지는 확인하기 어렵고, 수원국의 경제성과 개선이 예산지원에 기인한 것인지 파악하기는 불가능하다고 말한다. 그러면서 소득 빈곤(income poverty) 또는 비소득 빈곤(non-income poverty) 감소와 같은 장기적·간접적·긍정적인 효과가 예산지원에 의해 직접적 으로 나타난 것인지 알 수 없다고 설명한다. 


\section{IV. 결론 및 시사점}

새천년개발목표를 달성하기 위해 원조 효과성이 중요하다는 게 강조되었고, 이러한 원조 효과성을 제고하는 데 많은 기여를 할 것으로 예상되었던 예산지원사업이 2000년대 초반부터 여러 공여국 사이에서 활성화되었다. 그러나 10년이 지난 현재 다자를 제외한 많은 양자 공여국이 예산지원사업, 특히 일반예산지원을 보류하거나 중단해 해당 사업 유형은 많이 축소되었다. 이는 예산지원사업의 효과성이 검증되기는 했지만, 부패 스캔들과 같은 부정적인 효과들과 수원국의 빈곤 감소 및 지속 가능하고 포용적인 경제성장의 직접적인 인과관계에 대한 근거를 찾을 수 없다는 평가에 기인한다. 그로 인해 지금까지 예산지원을 통해 달성되었던 개발의 긍정적인 효과들이 지속되기 어렵게 되었다. 뿐만 아니라 수원국의 거시경제 안정성이 흔들리고, 공여국과 수원국 간의 개발 전략 및 정책 논의를 위한 정책 대화의 구조가 약화되었으며, 원조조화가 어렵게 되는 안 하느니만 못한 결과를 가져왔다.

앞서 증명된 예산지원의 여러 긍정적인 효과가 지속적으로 유지되지 위해서는 예산지원사업을 재정비해 다시 활성화할 필요가 있다. 이를 위해 우선, 예산지원사업이 모두가 예측한 만병통치약이 아님을 인정하고, 이를 통해 얻을 수 있을 것으로 기대했던 많은 효과를 현실적인 수준으로 정리하는 일부터 시작해야 한다. 단기적으로, 분야예산지원을 중심으로 재편하고 또 분야예산지원 에서 확실한 효과성을 보인 국가에 대해 장기적인 일반예산지원을 다시 시작하는 방법을 제안한다. 또한 앞서 나타난 부정적인 효과들을 상쇄할 수 있는 예산지원사업의 형성 및 이행 메커니즘을 찾아야 할 것이다. 그리고 정책 대화를 통해 수원국 정부의 부패 위험성을 차단할 수 있는 예산 관리 방법을 지속적으로 논의하면서 시민사회와 수원국 언론이 예산지원과 관련된 정보에 접근할 수 있도록 하는 것이다. 뿐만 아니라 예산지원의 낮은 예측 가능성을 개선할 방법을 모색해야 할 것이다. 수원국이 지출 조건을 어겼다는 이유로 공여국 간의 통합되지 않은 지출 결정과 지출 지연으로 인해 발생한 원조의 낮은 예측 가능성을 개선하기 위해서 지출 조건을 어겼을 경우의 수를 고려한 지출 프로세스를 고민해야 할 것이다. 그리고 예산지원과 빈곤 감소 사이의 직접적인 인과관계 파악이 어렵다고는 하나, 교육과 보건 같은 사회 서비스에 대한 수혜자들의 접근이 개선된 것을 감안했을 때 장기적으로 비소득 빈곤의 감소는 기대해 볼 수 있을 것이다. 따라서 빈곤 감소라는 궁극적이며 장기적인 목표 달성을 확인할 수 있는 논리적인 평가 틀이 마련되어야 할 것으로 보인다. 


\section{〈참고 문헌〉}

한국국제협력단. 2016. 『OECD DAC 통합통계보고지침』. 성남: 한국국제협력단.

ADE, ITAD and COWI. 2013a. "Joint Evaluation of Budget Support to Tanzania: Lessons Learned and Recommendations for the Future.” Final Report: Volume 1. Independent Evaluation jointly managed by the European Commission, the Ministry of Foreign Affairs of Denmark, Irish Aid, the Ministry of Foreign Affairs of the Netherlands, and the Ministry of Finance of Tanzania, avaliable at https://assets.publishing.service.gov.uk/ government/ uploads/system/uploads/attachment_data/file/306117/Budget-Support-Ta nzania-Volume1.pdf (접속일: 2018.10.25.).

. 2013b. "Joint Evaluation of Budget Support to

Tanzania: Lessons Learned and Recommendations for the Future.” Final Report: Volume 2. Independent Evaluation jointly managed by the European Commission, the Ministry of Foreign Affairs of Denmark, Irish Aid, the Ministry of Foreign Affairs of the Netherlands, and the Ministry of Finance of Tanzania, avaliable at https://www.gov.uk/government/uploads/ system/uploads/attachment_data/file/306119/Budget-Support-TanzaniaVolumeII.pdf (접속일: 2018.10.25.).

. 2013c. "Joint Evaluation of Budget Support to Tanzania: Lessons Learned and Recommendations for the Future." Summary. Independent Evaluation jointly managed by the European Commission, the Ministry of Foreign Affairs of Denmark, Irish Aid, the Ministry of Foreign Affairs of the Netherlands, and the Ministry of Finance of Tanzania, avaliable at https://ec.europa.eu/europeaid/sites/devco/ files/evaluation-budget-support-tanzania-1321-summary-2013_en.pdf (접 속일: 2018.10.25.).

Caputo, Enzo, Antonie de Kemp and Andrew Lawson. 2011. "Evaluation Insights: Assessing the Impacts of Budget Support: Case Studies in Mali, Tunisia and Zambia.” No. 2, October 2011. Paris: OECD DAC Network on Development Evaluation, avaliable at http://www.oecd.org/dac/ evaluation/dcdndep/48934753.pdf (접속일: 2018.11.05.). 
DANIDA. 2014. "Review of Budget Support Evaluations." Copenhagen: Ministry of Foreign Affairs of Denmark, avaliable at https://www. oecd.org/derec/denmark/Review-of-Budget-Support-Evaluation.pdf (접속 일: 2018.10.25.).

Dijkstra, Geske, and Antonie de Kemp. 2015. “Challenges in Evaluating Budget Support and How to Solve Them." Evaluation Vol.21(1): 83-98.

EU. 2017. "Budget Support: Trends and Result 2017." Luxembourg: Publications Office of the European Union, avaliable at https://ec. europa.eu/europeaid/sites/devco/files/budget-support-trends-results-201 7_en.pdf (접속일: 2018.11.05.).

FISCUS. 2014. "Synthesis of Budget Support Evaluation: Analysis of the Findings, Conclusions and Recommendations of seven Country Evaluations of Budget Support.” London: FISCUS, ADE, avaliable at https://ec.europa. eu/europeaid/sites/devco/files/strategic-evaluation-synthesis-ec-budgetsupport-1335-main-report-201411_en.pdf (접속일: 2018.11.05.).

Koeberle, Stefan, Zoran Stavreski, and Jan Walliser. 2006. "Budget Support as More Effective Aid? Recent Experiences and Emerging Lessons." Washington D.C.: World Bank, avaliable at https://openknowledge. worldbank.org/bitstream/handle/10986/6958/359670Budget0Support01PUB LIC1.pdf?sequence=1\&isAllowed=y（접속일: 2018.11.05.).

Krisch, Franziska, and Johannes Schmitt. 2015. “Accompanying Measures to Budget Support - Any Added Value?” DEval Policy Brief 05/2015, avaliable at https://www.deval.org/files/content/Dateien/Evaluierung/Policy\%20Briefs/ DEval_Policy\%20Brief_052015_Budgethilfe_en.pdf (접속일: 2018.10.25.). Lawson, Andrew. 2015. "Evaluation Insights: Evaluating the Impact of Budget Support: Conclusions and recommendations Based on a Synthesis of Seven Budget Support Evaluations.” No. 10, February 2015. Paris: OECD DAC Network on Development Evaluation, avaliable at http://www.oecd.org/ dac/evaluation/Evaluation-Insights-Evaluating-the-Impact-of-BS-noteFINAL.pdf (접속일: 2018.11.05.). 
OECD. 2006. "Harmonizing Donor Practices for Effective Aid Delivery. Volume 2: Budget Support, Sector Wide Approaches and Capacity Development in Public Financial Management.” DAC Guidelines and Reference Series. Paris: Organization for Economic Cooperation and Development, avaliable at http://www.oecd.org/development/effectiveness/34583142.pdf (접속일: 2018.11.05.).

2012. "Evaluating Budget Support: Methodological Approach.” Paris: Organization for Economic Cooperation and Development, avaliable at https://www.oecd.org/dac/evaluation/dcdndep/Methodological\%20approac h\%20BS\%20evaluations\%20Sept\%202012\%20_with\%20cover\%20Thi.pdf (접속일: 2018.11.05.).

. 2018. "Draft Revised Statistical Reporting Directives for DAC Statistics: Annexes - Modules A, B and C," avaliable at http://www.oecd.org/ officialdocuments/publicdisplaydocumentpdf/?cote=DCD/DAC/STAT(201 8)9/REV1/ADD1\&docLanguage=En（접속일: 2018.11.05.).

Orth, Magdalena, Johannes Schmitt, Franziska Krisch, and Stefan Oltsch. 2017. "What We Know About the Effectiveness of Budget Support: Evaluation Synthesis." Bonn: German Institute for Development Evaluation (DEval), avaliable at https://www.deval.org/files/content/Dateien/Evaluierung/Berichte/ 2017/DEval_Synthesen_Bericht_2017_EN_bf_V2_baf.pdf (접속일: 2018.10.25.). Orth, Magdalena, and Johannes Schmitt. 2018a. "How Effective is Budget Support as an Aid Modality?" DEval Policy Brief 2/2018, avaliable at https://www.deval.org/files/content/Dateien/Evaluierung/Policy\%20Briefs /DEval_Policy\%20Brief_2.18_Budgethilfe_EN_web.pdf (접속일: 2018.10.25.). Orth, Magdalena, Marius Birsan, and Gunnar Gotz. 2018b. "On the Future of Integrated Policy-based Development Cooperation.” Bonn: German Institute for Development Evaluation (DEval), avaliable at https://www. deval.org/files/content/Dateien/Evaluierung/Berichte/2018/DEval_EN_The \%20Future\%20of\%20Integrated\%20Policy-Based\%20Development\%20Coo peration.pdf (접속일: 2018.10.25.).

OECD 통계사이트: http://stats.oecd.org/ (접속일: 2018.11.06.). 